\title{
STEM/EELS Study of Fission Product Transport in Neutron Irradiated TRISO Fuel Particles (NSUF report)
}

Isabella J van Rooyen, Haiming Wen

December 2016

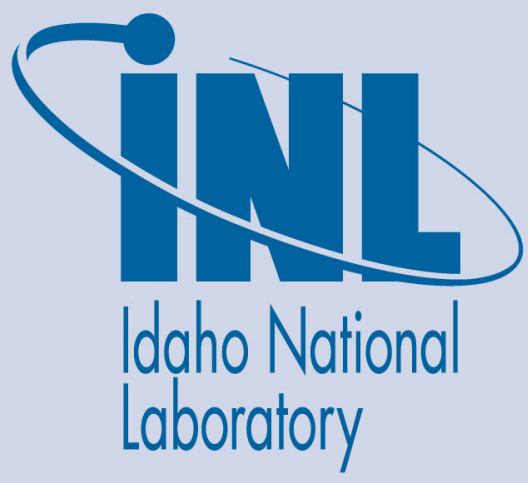

The INL is a U.S. Department of Energy National Laboratory operated by Battelle Energy Alliance 


\title{
STEM/EELS Study of Fission Product Transport in Neutron Irradiated TRISO Fuel Particles (NSUF report)
}

\author{
Isabella J van Rooyen, Haiming Wen
}

December 2016

Idaho National Laboratory Idaho Falls, Idaho 83415

http://www.inl.gov

Prepared for the

U.S. Department of Energy

Under DOE Idaho Operations Office

Contract DE-AC07-05ID14517 


\section{Annual Report Project Template}

\section{ALL FIELDS IN THIS TEMPLATE MUST BE FILLED OUT}

Submit a separate template for each individual awarded project that performed work during fiscal year 2015 (October 1, 2014 - September 30, 2015).

Finished reports should only be about two pages long including figures and graphics.

Refer to the Sample Annual Report Submission to make sure you are submitting your project correctly.

Questions? Contact Sarah Robertson, sarah.robertson@inl.gov or (208) 526-0490.

1. Project Title (from your proposal) STEM/EELS Study of Fission Product Transport in Neutron Irradiated TRISO Fuel Particles

2. University Principal Investigator Haiming Wen

3. INL Principal Investigator Isabella J van Rooyen

4. Team Member/Collaborator Information

\begin{tabular}{|c|c|c|c|c|c|}
\hline \multicolumn{3}{|c|}{ For All Team Members/Collaborators } & \multicolumn{3}{|c|}{ If a Student } \\
\hline Name & $\begin{array}{c}\text { Role } \\
\text { (Team Member } \\
\text { or Co-Principal } \\
\text { Investigator) }\end{array}$ & Institution & $\begin{array}{l}\text { Level } \\
\text { in } \\
\text { School }\end{array}$ & $\begin{array}{l}\text { Field of Studyl } \\
\text { Degree Seeking }\end{array}$ & $\begin{array}{l}\text { U.S. or } \\
\text { Non-U.S. }\end{array}$ \\
\hline Haiming Wen & Principal Investigator & Idaho State University & & & $\begin{array}{l}\square \text { U.S } \\
\square \text { Non-U.S. }\end{array}$ \\
\hline Isabella J van Rooyen & $\begin{array}{l}\text { Co-Principal } \\
\text { Investigator }\end{array}$ & $\begin{array}{l}\text { Idaho National } \\
\text { laboratory }\end{array}$ & & & $\begin{array}{l}\square \text { U.S. } \\
\square \text { Non-U.S. }\end{array}$ \\
\hline & & & & & $\begin{array}{l}\square \text { U.S. } \\
\square \text { Non-U.S. }\end{array}$ \\
\hline & & & & & \begin{tabular}{|l}
$\square$ U.S. \\
$\square$ Non-U.S.
\end{tabular} \\
\hline & & & & & $\begin{array}{l}\square \text { U.S. } \\
\square \text { Non-U.S. }\end{array}$ \\
\hline & & & & & $\begin{array}{ll}\square & \text { U.S. } \\
\square & \text { Non-U.S. }\end{array}$ \\
\hline
\end{tabular}

5. Degrees granted as a result of this research. (Please list any degrees from the start of your project award, even those from previous years.)

\begin{tabular}{|l|l|l|l|l|}
\hline Name & Institution & Degree & $\begin{array}{c}\text { Field of Study/Degree } \\
\text { Seeking }\end{array}$ & $\begin{array}{c}\text { Date } \\
\text { (molyr) }\end{array}$ \\
\hline & & & & \\
\hline & & & & \\
\hline & & & & \\
\hline
\end{tabular}


6. NSUF Facility used (check all that apply) NOTE: If facilities other than those specified below were used, they can be mentioned in the body text of the accomplishments section.)

Center for Advanced Energy Studies:

$\triangle$ Microscopy and Characterization Suite (MaCS)

Idaho National Laboratory:

Advanced Test Reactor (ATR)

Hot Fuel Examination Facility (HFEF)

Analytical Laboratory (AL)

Electron Microscopy Laboratory (EML)

Irradiation Assisted Stress Corrosion Cracking (IASCC) facility

Illinois Institute of Technology:

Materials Research Collaborative Access Team (MRCAT) facility

Massachusetts Institute of Technology:

Nuclear Reactor Laboratory

North Carolina State University:

$\square$ Nuclear Services Laboratories

$\square$ PULSTAR Reactor Facility

\section{Oak Ridge National Laboratory:}

$\square$ High Flux Isotope Reactor (HFIR)

$\square$ Irradiated Materials Examination and Testing Facility (IMET) Hot Cells

$\square$ Irradiated Fuels Examination Laboratory (IFEL) Hot Cells

$\square$ Radiochemical Engineering Development Center (Radiological Laboratories)

$\square$ Low Activation Materials Design and Analysis Laboratory (LAMDA)

Pacific Northwest National Laboratory:

Radiochemistry Processing Laboratory (RPL)

Materials Science \& Technology Laboratory (MSTL)

\section{Purdue University:}

Interaction of Materials with Particles and Components Testing (IMPACT) experimental facility

University of California, Berkeley:

Nuclear Materials Laboratory

University of Michigan:

$\square$ Michigan Ion Beam Laboratory

Irradiated Materials Complex

University of Nevada, Las Vegas:

Harry Reid Center Radiochemistry Laboratories

University of Wisconsin:

$\square$ Tandem Accelerator Ion Beam

Characterization Laboratory for Irradiated Materials

Westinghouse:

Materials Center of Excellence Laboratories

7. Introduction: Provide a brief introduction to the research. (50-150 words)

Tristructural isotropic (TRISO) coated fuel particles are designed for use as nuclear fuel particles in high temperature nuclear reactors. They are composed of a uranium oxide (UO2) or uranium oxy-carbide (UCO) fuel kernel protected by a series of ceramic coating layers that retain fission products. The ceramic TRISO coatings are a finely-tuned fission product containment system, which consist of, in the order of increased distance to the fuel kernel, 
a porous carbon buffer layer, an inner pyrolytic carbon (IPyC) layer, a SiC layer, and an outer PyC (OPyC) layer. The $\mathrm{SiC}$ layer is the primary fission product barrier of the TRISO particle and serves as the principal structural layer as well. Release of certain metallic fission products, e.g. Ag and Pd, through intact TRISO coatings has been evident for decades around the world, as well as in the recent AGR-1 experiment at Idaho National Laboratory. The release of $110 \mathrm{mAg}$ is a potential worker safety concern due to plate-out on the cooler metallic parts of the helium pressure boundary. This safety concern highlights the importance of identifying the metallic fission product transport mechanisms of $110 \mathrm{mAg}$ through the TRISO coating layers.

8. Project Description: Describe the technical objectives of the research and the benefits to the state-of-knowledge if successful. Also explain how this research is helping DOE meet its objectives of reliability, safety and life extension for current reactors, or how it helps develop improvements in new reactors. (200-300 words)

The objectives of this project are to study the distribution, composition and structure of fission products in neutron irradiated SiC layer of the TRISO particles, using electron microscopy including scanning transmission electron microscopy (STEM), energy dispersive x-ray spectroscopy (EDS), electron energy loss spectroscopy (EELS), high-resolution transmission electron microscopy (HRTEM) and precession electron diffraction (PED), in an effort to enhance the understanding of distribution, composition, structure and transport mechanisms of fission products. In the past 40 years, numerous studies, including reactor experiments, out-of-pile experiments, and simulations, have been performed to investigate the fission product transport behavior and mechanisms. Grain boundary (GB) diffusion, neutron-induced diffusion, catalytic Pd-assisted transport, and vapor-phase migration all have been suggested as possible governing transport mechanisms. The previous studies, however, have not been able to reproduce the transport behavior of fission products and the mechanisms remain poorly understood. This project is anticipated to contribute to enhancing the understanding of the mechanisms of fission product transport in irradiated SiC layer of the TRISO particles. Thorough understanding of fission product transport mechanisms in the SiC layer will improve fuel modeling and design and better SiC layers and TRISO coated particles can be designed to enhance retention of fission products and reduce their release. Eventually, TRISO coated particles with improved performance can be fabricated, and such advancement will expedite the qualifying and licensing processes for TRISO coated particles. Hence, this research is contributing to achieving the objectives of DOE-NE to develop the next generation nuclear reactors, particularly high-temperature gas reactors.

9. Accomplishments: Summarize the technical goals of the research and the accomplishments made toward these technical goals from the start of your awarded project (including work in previous years if applicable) through September 30, 2015 (end of fiscal year). Emphasize the particular accomplishments made toward the technical goals in fiscal year 2015 (October 1, 2014 - September 30, 2015). The Annual Report covers the fiscal year, not calendar year, so do not report on work performed after September 30, 2015. Please write all accomplishments in narrative form. (300-500 words)

Include contributions by all parties, naming the institution and, where appropriate, individuals involved. Discuss any obstacles encountered during the experiment. If someone has made an outstanding contribution, this is the place to make that acknowledgement.

The technical goals of the research are to determine the distribution, composition and structure of fission products in the $\mathrm{SiC}$ layer of a TRISO particle neutron irradiated to $3.6 \times 10^{\wedge} 21 \mathrm{n} / \mathrm{cm} 2$ fast fluence at $1040 \mathrm{oC}$, utilizing electron microscopy methods. STEM was used to investigate distribution of fission products; EDS in STEM was employed to obtain fission product composition; information on structure of fission products was acquired using HRTEM; precession electron diffraction (PED) derived ASTAR was executed to study characters of grain boundaries where fission products are located; attempts were made to measure charge states of precipitates using EELS. The experiments and data analyses were conducted by Haiming Wen, and the samples were from Advanced Microscopy and Microanalysis Program that Isabella van Rooyen is in charge of under the Advanced Gas Reactor Program of DOE-NE. Both Haiming Wen and Isabella van Rooyen participated in the design of the project. Accomplishments were made toward the technical goals. In summary, a high density of nanoscale fission product precipitates was observed in the SiC layer close to the SiC-IPyC interface, most of which are rich in Pd, while Ag was not identified. Some Pd-rich precipitates contain U. Precipitates tend to have complex structure. Although a precipitate appears to have uniform contrast in STEM, it may exhibit non-uniform contrast in TEM/HRTEM, which may be caused by composition variations throughout the precipitate (as indicated by EDS), and by variations in crystal structure, orientation or dislocation density among different parts of the precipitate (as suggested by HRTEM). ASTAR results indicate that majority of precipitates are located at random high-angle grain boundaries. Significant challenges were 
encountered during EELS study and no useful EELS results were obtained, and the challenges were ascribed to the fact that the TEM specimen is not thin enough. The TEM specimen was prepared previously in the Electron Microscopy Laboratory (EML), and due to the significant radioactivity, it could not be further thinned at CAES. In addition, it could not be shipped back to EML for further thinning due to the limit in time and budget for this RTE project. Although the EELS study was not sucessful, the other data (STEM, EDS, TEM/HRTEM and ASTAR) enabled significant accomplishments toward the technical goals, which rendered this project successful.

Figure 1 shows TEM and STEM images of a fission product precipitate and EDS line scan and mapping results. In TEM images ((a) and (b)), there is contrast variation throughout the precipitate, although the precipitate appears to have uniform contrast in STEM image ((c)). EDS line scan and mapping indicate that the precipitate is rich in Pd, however, there is variation in Pd concentration throughout the precipitate. Note that $\mathrm{Si}$ and $\mathrm{C}$ concentrations are from the $\mathrm{SiC}$ matrix.

Figure 2 displays STEM, ASTAR and EELS results. The ASTAR results indicate that the precipitate highlighted in (a) is located at a random high-angle grain boundary with a misorientation angle of 30o. Note that this precipitate is the same with the one studied in Figure 1. Although it is clear from EDS results that this precipitate is Pd-rich, no peak corresponding to Pd is evident in the EELS spectrum ((c)); the only peak present in the EELS spectrum corresponds to $\mathrm{C}$ (that comes from the $\mathrm{SiC}$ matrix). From the zero-loss peak ((d)), the thickness of the precipitate is computed as 0.54 electron mean free path, which is too thick to get good EELS results. In order to obtain good EELS signals, the thickness needs to be on the order of 0.1 to 0.2 electron mean free path. Thickness measurements were conducted using EELS at many different locations, and it was found that the TEM specimens is too thick for EELS study.

Figure 3 shows TEM, HRTEM, STEM and EDS results on another fission product precipitate. From the TEM and HRTEM images, there is contrast variation across the precipitate, and it appears that there are multiple layers in the precipitate in the thickness direction of the TEM specimen. From the HRTEM images, it appears that the parts with different contrast in the precipitate have the same crystal structure, however, they may have slightly different orientation and/or dislocation density. The contrast in the precipitate in the STEM image is uniform, and EDS point scan result indicate that this precipitate is rich in Pd, with a U concentration.

STEM, EDS, TEM and HRTEM results on another fission product precipitate are displayed in Figure 4. In the STEM image, the precipitate has uniform contrast. The EDS results indicate that the precipitate is rich in Pd. Note that the $\mathrm{Cu}$ concentration is from the TEM grid. Multiple EDS point scans indicate that there are variations in Pd concentration across the precipitate. Similarly, in TEM and HRTEM images, there are contrast variations among different parts of the precipitate. From HRTEM images, the precipitate appears to have a face centered cubic structure, and different parts of the precipitate have the same structure. The contrast variations may be caused by variations in Pd concentration, and by slightly different orientation and/or dislocation density.

10. Future Activities: What are the future goals for this research in 2016? (Fiscal year 2016 began October 1, 2015 and ends September 30, 2016). (20-150 words)

This project is now complete.

11. Publications: Include conference, journal, textbook and special workshop reports. List the citations in text form here and on the website. To load on the website, log in to the NSUF website and select the project from "My NSUF." Click the "+" in the header for Book/Journal Publications and follow the instructions. Publications are tracked electronically to be included in the publications archive on the NSUF website and used for metric analysis. Only publications from the current fiscal year will be included in the annual report, but all publications need to be loaded on the website so they are included in the archive.

1. Haiming Wen, Isabella J. van Rooyen, "Advanced electron microscopy study of fission products in a TRISO coated particle neutron irradiated to 3.6 x $10^{\wedge} 21 \mathrm{n} / \mathrm{cm} 2$ fast fluence at $1040 \mathrm{oC}$ ", International Conference on Nuclear Materials 2017, June 25-26, Paris, France, accepted.

2. Haiming Wen, Isabella J. van Rooyen, "Distribution, composition and structure of fission products in a TRISO coated particle neutron irradiated to $3.6 \times 10^{\wedge} 21 \mathrm{n} / \mathrm{cm} 2$ fast fluence at $1040 \mathrm{oC}$ ", journal paper in preparation.

12. Staff exchanges (if any).

Click here to enter text.

\section{Patents applied for because of this research.}

Click here to enter text. 
14. Quote from PI or a student. Please include the name and title of the individual quoted.

The advanced electron microscopy techniques available at CAES provide great tools for studying

Quote: structure and composition of fission products in neutron irradiated nuclear fuels.

Name: Haiming Wen

Title: $\quad$ Research Assistant Professor

15. Write one sentence on why this project is important. What is the "wow" factor? This will become one of the call-outs on your project pages so it is not a quote, just something you would like brought to the attention of the reader (e.g.,"Triplex $\mathrm{SiC}$ composite cladding has great potential for improving fuel behavior during loss of coolant accidents." Or "Developing inert matrix fuels will reduce radiotoxic waste and thus provide the world with a sustainable fuel cycle." Or "This experiment will provide necessary data for the development of a fast neutron test capability at ATR.")

Understanding of fission products in irradiated TRISO fuel particles will facilitate design and fabrication of TRISO particles with improved performance and expedite the development and deployment of high-temperature gas reactors.

16. Graphics (only high-resolution, $300 \mathrm{dpi}$, .jpeg, .tif, .pdf, and eps file formats only). Please include pertinent, high-quality graphics with captions. Along with uploading the individual high resolution .jpeg, .tiff pdf or eps files, please include your graphics in the text of your Word document report to indicate where each graphic belongs. Refer to the Sample Annual Report Submission for examples of the correct way to submit artwork. If you need assistance with your figures, please contact Sarah Robertson. Limit of four graphics. 


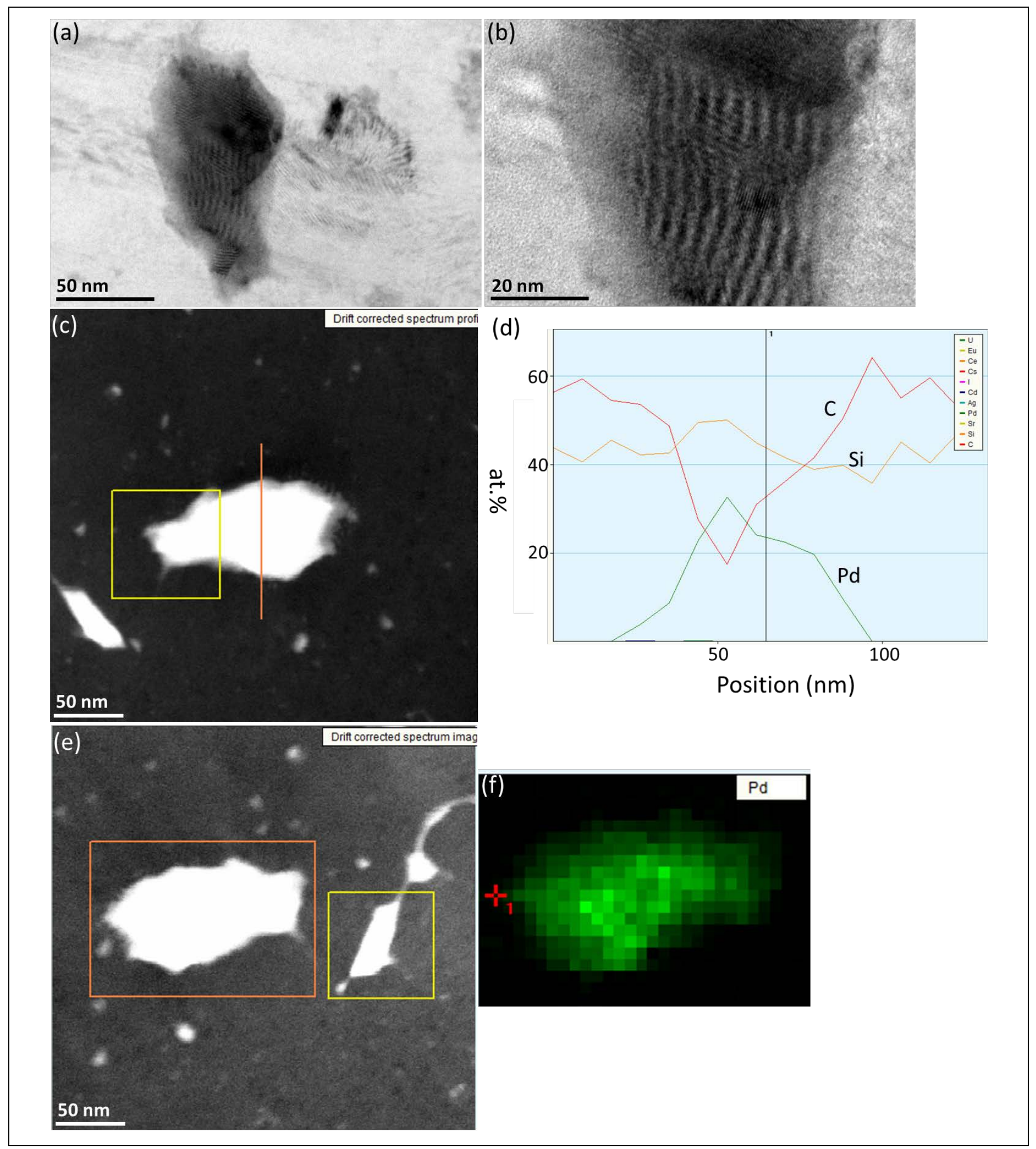

Figure 1. (a) (b) TEM images of a fission product precipitate; (c) STEM image of the same fission product precipitate where the line indicates EDS line scan and the square represents a reference area for drift correction during EDS line scan; (d) EDS line scan results corresponding to (c); (e) STEM image of the same fission product precipitate where the orange rectangle indicates EDS mapping area and the yellow square represents a reference area for drift correction during EDS mapping; (f) Pd map corresponding to EDS mapping area in (e). 

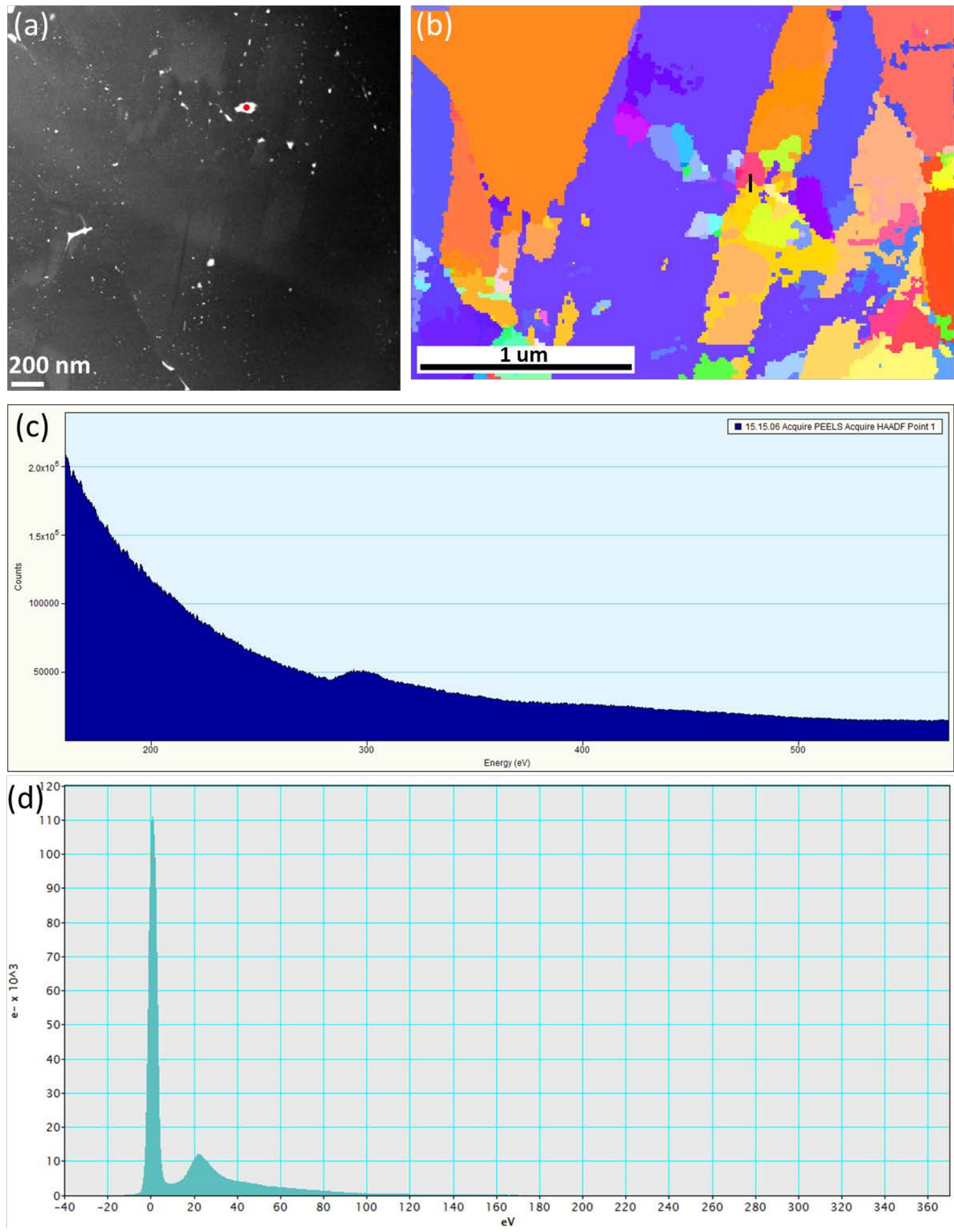

Figure 2. (a) STEM image; (b) precession electron diffraction derived ASTAR map, where the fission product precipitate highlighted in (a) with a red spot is located at a grain boundary indicated by a black line (the black line is drawn during ASTAR data analysis across the grain boundary so that the characteristics of the grain boundary are obtained); (c) EELS spectrum corresponding to the precipitate highlighted in (a); (d) zero-loss peak of the EELS spectrum corresponding to the precipitate highlighted in (a). 


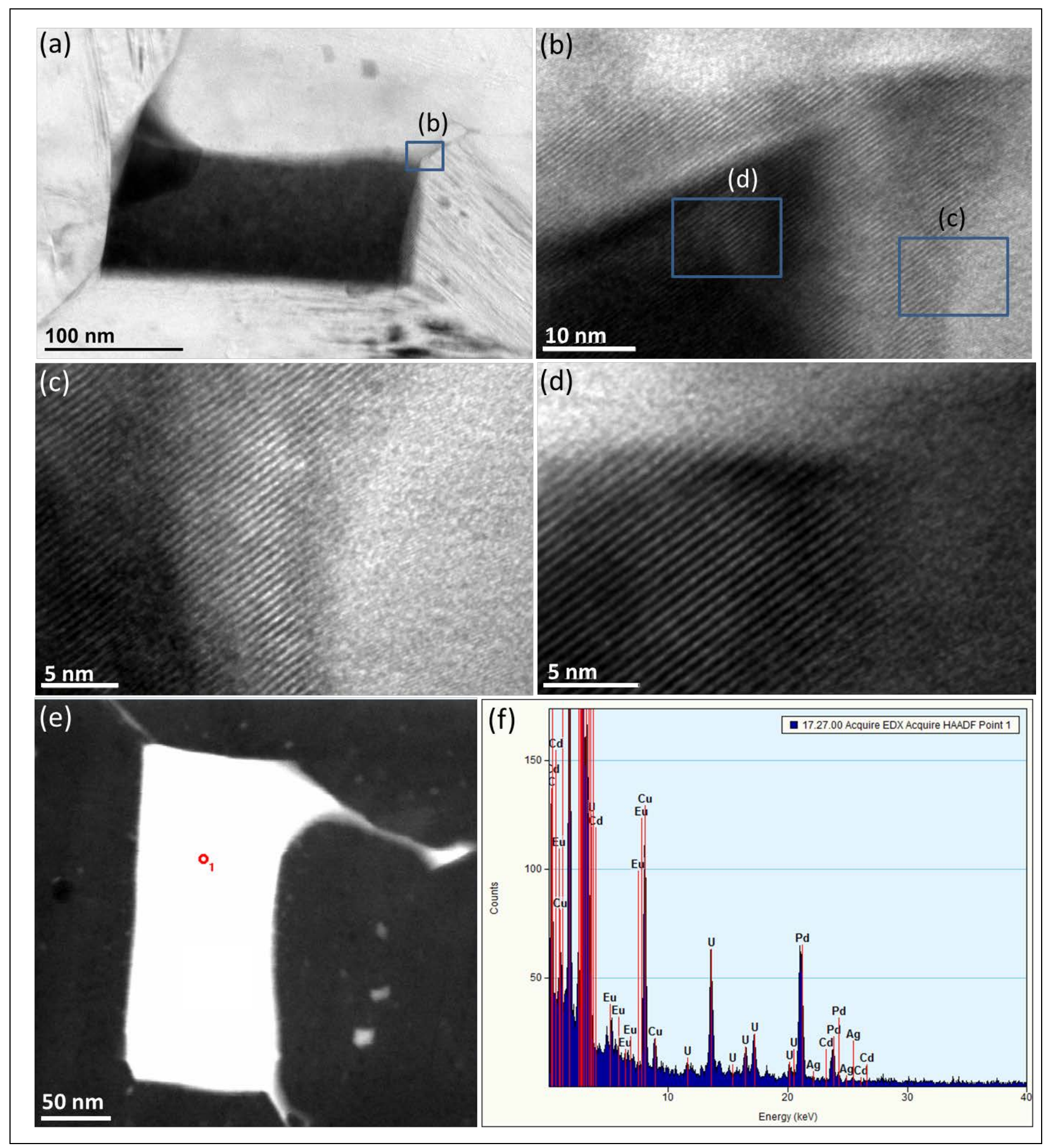

Figure 3. (a) TEM image of a fission product precipiate; (b) (c) (d) high-resolution TEM images of the fission product precipitate in (a), where the rectangular areas indicated in (b) are magnified in (c) and (d) respectively; (e) STEM image of the same fission product precipitate; (f) EDS spectrum corresponding to the EDS point scan indicated in (e). 

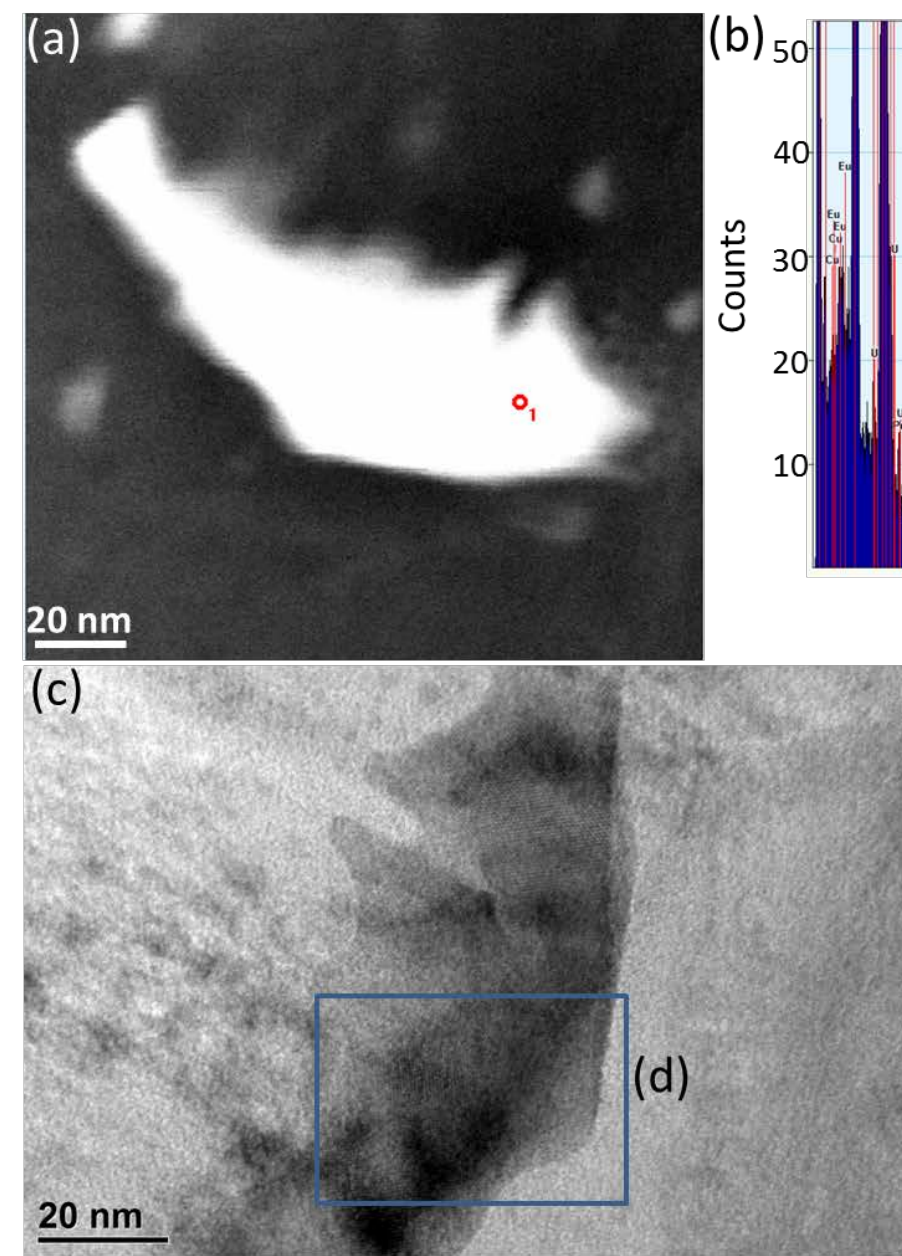

(e) $5 \mathrm{~nm}$
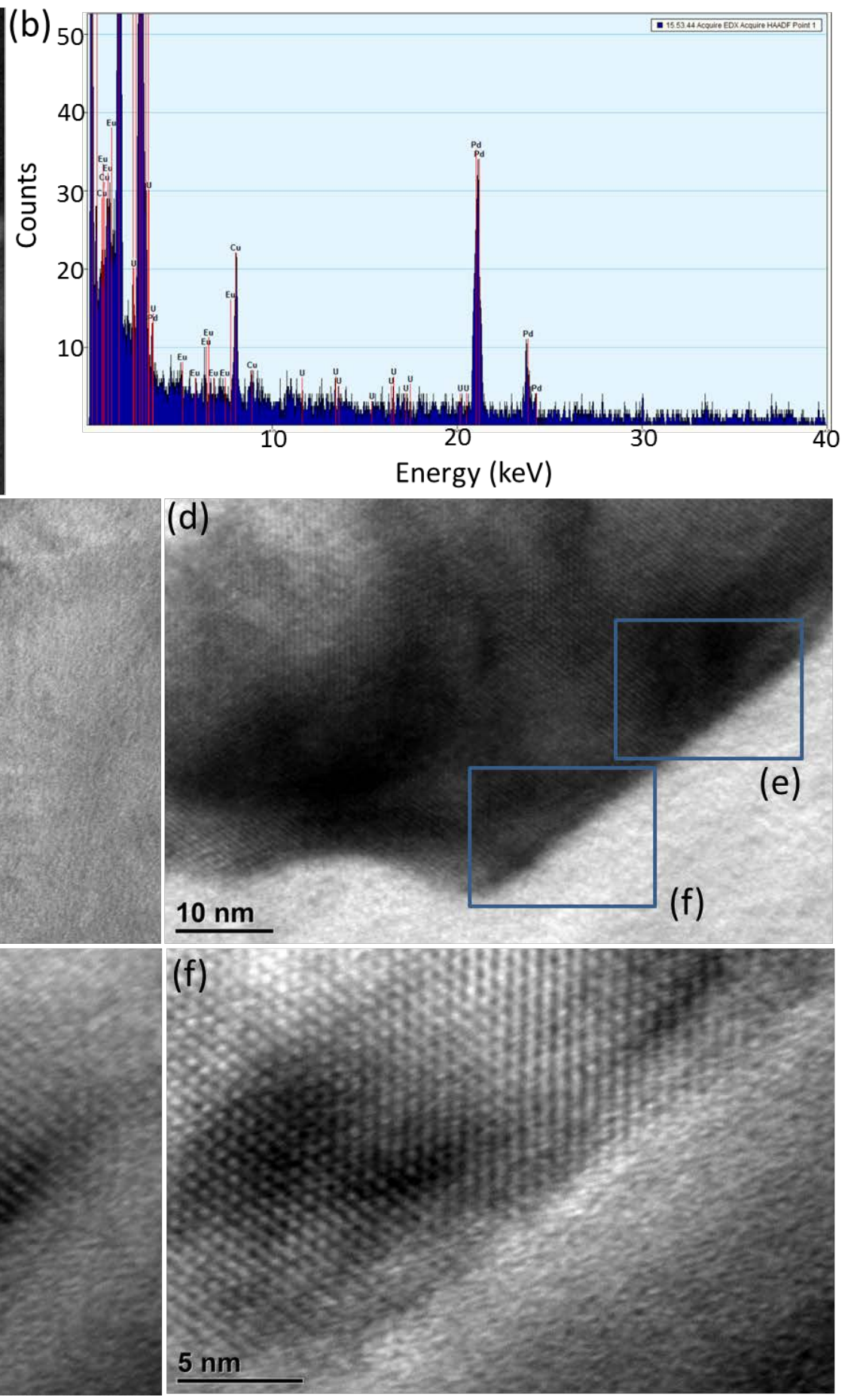

Figure 4. (a) STEM image of a fission product precipitate where the red circle indicates the position for a EDS point scan; (b) EDS spectrum corresponding to the EDS point scan indicated in (a); (c) TEM image of the same fission product precipitate shown in (a); (d) (e) (f) high-resolution TEM images of the precipitate indicated in (c), where the rectangles in (d) are magnified in (e) and (f) respectively. 